\title{
Longitudinal change in arterial stiffness after delivery in women with preeclampsia and normotension: a prospective cohort study
}

Sehun KIM${ }^{1}$, Hyun Ja LIM², Jeung-Ran $\mathrm{KIM}^{3}$, Kyung Joon $\mathrm{OH}^{4}$, Joon-Seok $\mathrm{HONG}^{4^{*}}$ and Jung-Won $\mathrm{SUH}^{3^{*}}$ (D)

\begin{abstract}
Background: Preeclampsia is associated with increased arterial stiffness during pregnancy. However, data on the longitudinal change in arterial stiffness after delivery in women with preeclampsia are lacking. In this pilot study, we aimed to examine the longitudinal change in arterial stiffness using the cardio-ankle vascular index after delivery in women with preeclamptic and normotensive pregnancies.

Methods: We enrolled pregnant women with preeclampsia $(n=37)$ and normotension $(n=36)$ who gave birth at Seoul National University Bundang Hospital between March 2013 and May 2016, and followed-up at day 1, 6 months, and 12 months after delivery. The longitudinal change in the cardio-ankle vascular index and other variables (blood pressure, lipid profiles, serum creatinine, and liver enzymes) were compared between the two groups using the mixed-effects model, and interactions among the main predictors were examined.

Results: The longitudinal change in the cardio-ankle vascular index did not significantly differ between the two groups ( $\beta=0.11,95 \% \mathrm{Cl}:-0.31-0.54, p=0.60$ ). Predictors of the longitudinal change in the cardio-ankle vascular index included age, time since delivery, body mass index, and diabetes mellitus. Women with preeclampsia showed significantly elevated blood pressure, lipid profiles, serum creatinine, and liver enzymes compared to women with normotension over the course of 1 year of follow-up.
\end{abstract}

Conclusions: Preeclampsia is associated with unfavorable blood pressure and metabolic indices after delivery. However, we found no difference in the longitudinal change in arterial stiffness between women with preeclampsia and normotension over the course of 1 year after delivery.

Trial registration: Retrospectively registered at ClinicalTrials.gov on October 29, 2019 (NCT04142268).

Keywords: Blood pressure, Cardiovascular diseases, Cardio-ankle vascular index, Longitudinal change, Preeclampsia, Pregnancy, Vascular stiffness

\footnotetext{
* Correspondence: hjsobgy@gmail.com; dasome2@snu.ac.kr

${ }^{4}$ Department of Obstetrics and Gynecology, Seoul National University

Bundang Hospital, Seoul National University College of Medicine, 82 Gumi-ro,

173 Beon-gil, Bundang-gu, Seongnam 13620, Republic of Korea

${ }^{3}$ Department of Internal Medicine, Cardiovascular Center, Seoul National

University Bundang Hospital, Seoul National University College of Medicine,

82 Gumi-ro, 173 Beon-gil, Bundang-gu, Seongnam 13620, Republic of Korea

Full list of author information is available at the end of the article
}

(c) The Author(s). 2020 Open Access This article is licensed under a Creative Commons Attribution 4.0 International License, which permits use, sharing, adaptation, distribution and reproduction in any medium or format, as long as you give appropriate credit to the original author(s) and the source, provide a link to the Creative Commons licence, and indicate if changes were made. The images or other third party material in this article are included in the article's Creative Commons licence, unless indicated otherwise in a credit line to the material. If material is not included in the article's Creative Commons licence and your intended use is not permitted by statutory regulation or exceeds the permitted use, you will need to obtain permission directly from the copyright holder. To view a copy of this licence, visit http://creativecommons.org/licenses/by/4.0/ The Creative Commons Public Domain Dedication waiver (http://creativecommons.org/publicdomain/zero/1.0/) applies to the data made available in this article, unless otherwise stated in a credit line to the data. 


\section{Background}

Hypertensive pregnancy disorders, such as preeclampsia or eclampsia, are one of the leading causes of maternal mortality during pregnancy and the puerperium, affecting $2-8 \%$ of gestations [1-3]. These disorders are associated with vascular endothelium dysfunction, insulin resistance, hyperlipidemia, hypercoagulability, and inflammation [4-6]. Thus, hypertensive pregnancy disorders share many etiologies with cardiovascular disease. There is accumulating evidence that women with a history of hypertensive pregnancy disorders have increased risks of cardiovascular disease [7, 8].

Arterial stiffening develops from a complex interaction between stable and dynamic changes in the structural and cellular elements of the vessel wall [9]. Furthermore, arterial stiffening is a marker for increased cardiovascular risks such as myocardial infarction, heart failure, and total mortality [10]. Previous studies suggest that women with preeclampsia have increased arterial stiffness during pregnancy compared to pregnant women with normotension $[11,12]$. However, there are few reports on the longitudinal change in arterial stiffness after delivery in women with preeclampsia.

In the present pilot study, we aimed to longitudinally follow arterial stiffness, as assessed by the cardio-ankle vascular index (CAVI), blood pressure (BP) and other metabolic indices, for 1 year after delivery. Furthermore, we investigated the predictive markers of increased postpartum arterial stiffness.

\section{Materials and methods}

\section{Study participants}

This prospective cohort study included 37 women with preeclampsia and 36 women with normotension who gave birth at Seoul National University Bundang Hospital (SNUBH) between March 2013 and May 2016. SNUBH is a teaching and tertiary referral hospital that provides care for high-risk deliveries. Women ages 18 to 45 were eligible for the study. We excluded women with a pregnancy that ended in stillbirth, and those who were hemodynamically compromised or had peripartum bleeding complications.

The diagnosis of preeclampsia was made based on the criteria of the International Society for the Study of Hypertension in Pregnancy. Under this classification, preeclampsia is defined as diastolic BP of at least 110 $\mathrm{mmHg}$ on one occasion or diastolic BP of at least 90 $\mathrm{mmHg}$ on two consecutive occasions more than $4 \mathrm{~h}$ apart, in combination with proteinuria ( $\geq 300 \mathrm{mg}$ total protein in a 24-h urine collection or, if this is not available, $\geq 2+$ proteinuria by dipstick analysis on two consecutive occasions at least $4 \mathrm{~h}$ apart) that develops after 20 weeks of gestation in women who were previously normotensive [13].
Study participants were treated at the physician's discretion according to current recommendations and guidelines for the peripartum and postpartum periods.

\section{Study protocol}

The CAVI is calculated based on the stiffness parameter, and is theoretically independent of changes in BP. Because of this distinct advantage, the CAVI has been applied clinically to assess arterial stiffness in patients with known cardiovascular diseases (atherosclerosis, coronary heart disease, and stroke), as well as in those at risk for cardiovascular diseases (hypertension, diabetes, obesity, and advanced age) [14-16].

The CAVI was measured on day 1, 6 months, and 12 months after delivery in both study groups.

The body mass index (BMI), BP, lipid profiles, serum creatinine, aspartate transaminase (AST), and alanine transaminase (ALT) levels were assessed simultaneously with the CAVI.

\section{Laboratory measurements}

Blood samples were collected from the antecubital vein after $8-10 \mathrm{~h}$ of fasting. Laboratory performance was monitored regularly by a quality control program. Hemoglobin was measured using the XE-2100 D (Sysmex Inc., Kobe, Japan). Serum creatinine, ALT, AST, total cholesterol, high-density lipoprotein (HDL) cholesterol, low-density lipoprotein (LDL) cholesterol, and triglyceride (TG) levels were measured using the Beckman Coulter AU 5800 analyzer (Beckman Coulter Inc., Brea, CA, USA).

\section{Measurement of BP and the CAVI}

After the study participant had rested in a seated position for at least $5 \mathrm{~min}$, BP was measured three times on the right arm, using an appropriately sized arm cuff and validated upper arm BP monitor (HEM-7200; Omron healthcare Co., Kyoto, Japan) [17]. The final BP value was obtained by averaging the second and third measurements. Height and body weight were measured during each visit using standardized equipment (G-310c, GTech Co., Uijeongbu, South Korea).

The CAVI was measured in the supine position using a Vasera VS-1000 vascular screening system (Fukuda Denchi, Tokyo, Japan). The principles of the CAVI have been described in previous reports $[16,18]$. The automatically obtained data from the right and left CAVIs were analyzed using VSS-10 software. The average values of the right and left CAVIs were used for analysis.

\section{Statistical analysis}

Data distribution was examined and checked for potential outliers. Descriptive statistics were used to summarize the baseline demographic and clinical 
characteristics of the study participants. Group differences were evaluated using a t-test or the Wilcoxon test for continuous variables, and the Chi-square test or Fisher's exact test for categorical variables.

The relationship between the presence of preeclampsia and longitudinal changes in the CAVI, with and without control for other potential covariates, was examined using a mixed-effects model with compound symmetry covariance structure to adjust for repeated measurements within participants. The mixed-effects model accounted for all available data points, therefore, respondents with incomplete datasets were not excluded from analysis (under the assumption that missing data occurred at random). Interactions among the main predictors in the final model were examined. For the mixed-effects model, $\mathrm{R}^{2}$ as the proportion of explained variance can be categorized into two types: marginal $R^{2}\left(R_{(m)}^{2}\right)$ and conditional $R^{2}\left(R_{(\mathrm{C})}^{2}\right)$. $R^{2}{ }_{(\mathrm{m})}$ is concerned with variance explained by fixed effects. $R^{2}{ }_{(C)}$ is concerned with variance explained by both fixed effects and random effects. Thus, differences between corresponding $R^{2}{ }_{(m)}$ and $R^{2}{ }_{(\mathrm{C})}$ values reflect how much variability is in random effects $[19,20]$. Group differences were also evaluated across the reporting time points for several other physiological parameters of interest using mixed-effects modeling.
All reported $p$-values are 2-tailed, and $\alpha=0.05$ was set as a threshold for statistical significance. All statistical analyses were performed using SAS version 9.4 (SAS Institute, Cary, NC, USA).

\section{Results}

Study flow

The study flow is depicted in Fig. 1. The overall follow-up rate was $76.7 \%(n=56)$ and $61.6 \%(n=45)$ at 6 and 12 months, respectively. There was no difference in the follow-up loss rate at 1 year between the two groups $(p=0.81)$. There were no clinical events in either group such as death, myocardial infarction, or hospitalization from heart failure or renal deterioration. Participants who dropped out of the study indicated that they did not have time to participate due to infant care. CAVI measurements were performed in 71 women $(97.2 \%)$ at baseline, 50 women $(68.5 \%)$ at 6 months, and 45 women $(61.6 \%)$ at 12 months.

\section{Baseline characteristics}

The baseline characteristics of the study participants are shown in Table 1. There was no significant difference in the baseline mean CAVI between the control and preeclampsia groups $(6.92 \pm 1.69$ vs $6.53 \pm 1.5, p=0.306)$. However, compared to those in the control group, the

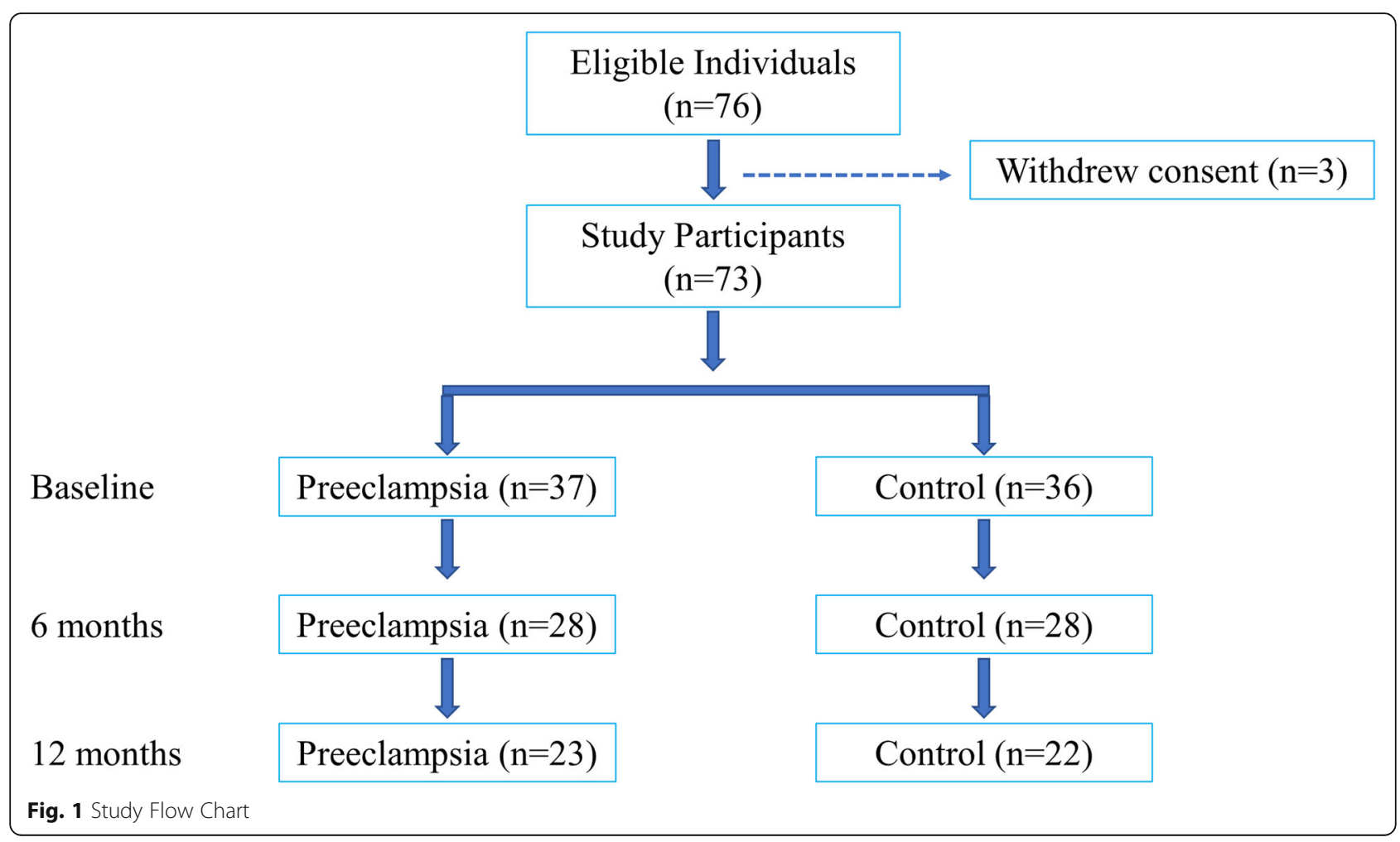


Table 1 Baseline demographic and clinical characteristics

\begin{tabular}{|c|c|c|c|}
\hline Variable & Preeclampsia $(n=37)$ & Control $(n=36)$ & $P$ value $^{a}$ \\
\hline Age, years & $34.8 \pm 3.6$ & $32.9 \pm 3.6$ & 0.029 \\
\hline History of preeclampsia, n (\%) & $2(5.4)$ & $1(2.8)$ & 0.999 \\
\hline \multicolumn{4}{|l|}{ Onset of preeclampsia, n (\%) } \\
\hline Early onset & $22(59.5)$ & & \\
\hline Late onset & $15(40.5)$ & & \\
\hline Peak body weight during pregnancy, kg & $70.4 \pm 11.8$ & $65.6 \pm 7.5$ & $0.042\left(0.108^{b}\right)$ \\
\hline Primipara & $24(64.9)$ & $24(66.7)$ & 0.871 \\
\hline Twins, n (\%) & $4(10.8)$ & $1(2.8)$ & 0.358 \\
\hline Gestational week at delivery & $33.7 \pm 3.0$ & $37.7 \pm 2.0$ & $<0.001$ \\
\hline Fetal birth weight, $\mathrm{kg}$ & $1.79 \pm 0.58$ & $2.93 \pm 0.52$ & $<0.001$ \\
\hline Waist-to-hip ratio & $0.92 \pm 0.05$ & $0.92 \pm 0.06$ & 0.874 \\
\hline BMI, $\mathrm{m}^{2} / \mathrm{kg}$ & $27.4 \pm 5.0$ & $25.0 \pm 2.8$ & $0.015\left(0.050^{\mathrm{b}}\right)$ \\
\hline Mean $C A V l^{c}$ & $6.92 \pm 1.69$ & $6.53 \pm 1.50$ & $0.306\left(0.032^{b}\right)$ \\
\hline Hypertension ${ }^{d}, \mathrm{n}(\%)$ & $2(5.4)$ & 0 & 0.494 \\
\hline Diabetes mellituse ${ }^{\mathrm{e}}, \mathrm{n}(\%)$ & $4(10.8)$ & 0 & 0.115 \\
\hline $\mathrm{SBP}, \mathrm{mmHg}$ & $142.4 \pm 12.7$ & $111.4 \pm 10.5$ & $<0.001$ \\
\hline $\mathrm{DBP}, \mathrm{mmHg}$ & $83.9 \pm 9.3$ & $63.2 \pm 7.8$ & $<0.001$ \\
\hline Hemoglobin, mg/dL & $12.0 \pm 2.0$ & $11.4 \pm 1.8$ & 0.164 \\
\hline Total cholesterol, mg/dL & $232.6 \pm 49.6$ & $208.6 \pm 46.3$ & 0.036 \\
\hline HDL cholesterol, mg/dL & $59.9 \pm 14.6$ & $62.6 \pm 13.1$ & 0.419 \\
\hline LDL cholesterol, mg/dL & $126.2 \pm 33.0$ & $112.2 \pm 33.7$ & $0.082\left(0.017^{b}\right)$ \\
\hline Triglyceride, mg/dL & $255.6 \pm 92.5$ & $213.6 \pm 60.5$ & $0.026\left(0.061^{b}\right)$ \\
\hline Creatinine, $\mathrm{mg} / \mathrm{dL}$ & $0.693 \pm 0.255$ & $0.532 \pm 0.092$ & $0.001\left(0.007^{b}\right)$ \\
\hline AST, IU/L & $31.0 \pm 17.2$ & $17.9 \pm 7.6$ & $<0.001$ \\
\hline $\mathrm{ALT}, \mathrm{IU} / \mathrm{L}$ & $27.0 \pm 26.9$ & $11.4 \pm 6.2$ & $0.002\left(<0.001^{b}\right)$ \\
\hline Hypertension treatment, n (\%) & $23(62.2 \%)$ & $0 \%$ & $<0.001$ \\
\hline \multicolumn{4}{|l|}{ Treatment regimen, $\mathrm{n}(\%)$} \\
\hline Single drug & $13(56.5)$ & & \\
\hline Two drugs & $8(34.8)$ & & \\
\hline Three drugs & $2(8.7)$ & & \\
\hline \multicolumn{4}{|l|}{ Type of antihypertensive drug, n (\%) } \\
\hline $\mathrm{CCB}$ & $23(100 \%)$ & & \\
\hline BB & $2(8.7 \%)$ & & \\
\hline
\end{tabular}

Data are presented as numbers and percentages or mean \pm SD. ${ }^{\mathrm{a}}$ T-test or Chi-square test. ${ }^{\mathrm{b}}$ The Mann-Whitney test was used due to a skewed distribution. ${ }^{\mathrm{c}}$ The

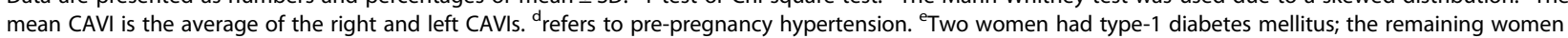
had type-2 diabetes mellitus

SD Standard deviation, BMI Body mass index, CAVI Cardio-ankle vascular index, SBP Systolic blood pressure, DBP Diastolic blood pressure, HDL High density lipoprotein, LDL Low density lipoprotein, AST Aspartate aminotransferase, ALT Alanine aminotransferase, CCB Calcium channel blocker, $B B$ Beta blocker

women in the preeclampsia group were significantly older (34.8 \pm 3.6 years vs $32.9 \pm 3.6$ years, $p=0.029)$, and had significantly higher systolic BP $(142.4 \mathrm{mmHg}$ vs $111.4 \mathrm{mmHg} \quad p<0.001)$ and diastolic BP (83.9 $\mathrm{mmHg}$ vs $63.2 \mathrm{mmHg}, p<0.001)$. There were also significant differences between the two groups in the baseline levels of total cholesterol, triglyceride, creatinine, AST, and ALT. Furthermore, 62.2\% (23/37) of the women with preeclampsia were treated with antihypertensive drugs. A calcium-channel blocker $(n=$ $23,100 \%)$ was the most prescribed antihypertensive agent; however, two women were also prescribed beta-blockers. In patients with preeclampsia, 22 had early-onset preeclampsia (defined as preeclampsia that develops before 34 weeks of gestation), whereas 15 had late-onset preeclampsia. 


\section{Relationship between preeclampsia and longitudinal change in the CAVI}

Both between-subject (group) and within-subject (time) differences in the mean CAVI were analyzed. At 6 months, the mean CAVI was higher in the preeclampsia group than in the control group (6.64 vs 6.23, $p=0.03$ ). However, at 12 months, the group difference did not remain significant (Table 2, Fig. 2). For the preeclampsia group, the mean CAVI showed a decreasing trend over 1 year; however, the trend was not statistically significant. For both groups, the within-subject comparisons in the mean CAVI between time points did not reveal any significant differences (Table 3, Fig. 2).

\section{Predictors of the longitudinal change in the CAVI}

After adjusting for the time since delivery, age, BMI, and diabetes mellitus, there was no difference in the longitudinal change in the mean CAVI between the two groups $(\beta=0.11,95 \%$ confidence interval [C.I]: $-0.31-0.54$, $p=0.60)$. No interaction between group and time was observed in this mixed-effects model $(p=0.2488)$.

The mixed-effects model indicated that the time since delivery $(\beta=-0.54,95 \%$ C.I: $-0.97--0.11, p=0.015)$, presence of diabetes mellitus $(\beta=1.07$, 95\% C.I: $0.25-$ 1.89, $p=0.012)$, age $(\beta=0.08,95 \%$ C.I: $0.02-0.14, p=$ $0.013)$, and BMI $(\beta=-0.07,95 \%$ C.I: $-0.12-0.03, p=$ 0.003 ) were significant predictors of the longitudinal change in the CAVI. No interactions were observed among any of the covariates in the mixed-effects model (Table 4).

In addition, when $R^{2}$ was considered as the proportion of explained variance, substantial differences between marginal $R^{2}$ and conditional $R^{2}$ in the mixed-effects models were observed. This indicates that a substantial amount of variability was in random effects.

\section{Relationships between preeclampsia and BP/metabolic indices}

Compared to the control group, the preeclampsia group had significantly higher age- and time-adjusted levels of systolic BP $(\beta=21.6,95 \%$ C.I: $15.9-27.4, p<0.0001)$, diastolic BP $(\beta=16.1,95 \%$ C.I: $12.0-20.2, p<0.0001)$, waist $/$ hip ratio $(\beta=0.04,95 \%$ C.I: $0.01-0.07, p=0.016)$, total cholesterol ( $\beta=20.5$, 95\% C.I: $2.08-38.8, p=0.03$ ),

Table 2 Between-subject (group) differences in the mean CAVI ${ }^{a}$ at each time point

\begin{tabular}{lllll}
\hline & Time & Control & Preeclampsia & $P$-value \\
\hline Mean CAVI & Day 1 & $6.53(6.01,7.05)$ & $6.92(6.36,7.48)$ & 0.31 \\
& 6 months & $6.23(5.91,6.55)$ & $6.64(6.41,6.86)$ & 0.03 \\
& 12 months & $6.58(6.38,6.79)$ & $6.20(5.75,6.65)$ & 0.09 \\
\hline
\end{tabular}

Data are presented as mean and $95 \%$ C.I. ${ }^{\text {a }}$ The mean CAVI is the average of the right and left CAVIs

CAVI Cardio-ankle vascular index, C. I Confidence interval triglyceride ( $\beta=31.7,95 \%$ C.I: $0.41-62.9, p=0.047)$, creatinine $(\beta=0.115$, 95\% C.I: $0.032-0.197, p=0.007)$, AST $(\beta=4.78,95 \%$ C.I: $1.22-8.35, p=0.009)$, and ALT $(\beta=$ 7.23, 95\% C.I: $1.53-12.9, p=0.014$ ) during follow-up (Table 5). However, no group differences were observed in the LDL cholesterol, and HDL cholesterol.

\section{Discussion}

\section{Principal findings}

The difference between the groups at 6 months, i.e. the higher mean CAVI in the preeclampsia group, appeared to be related to the older age of the women and the diabetic status, as the group difference was resolved with adjustment. However, by 1 year post delivery, there was no statistically significant difference in the CAVI between the groups. Both groups showed a statistically significant decline in the CAVI by 6 months after delivery and no subsequent meaningful change. There was no statistical evidence that this improvement was dependent on other factors.

Thus, although women with preeclamptic pregnancies persistently showed worse cardiovascular risk profile trajectories after delivery than women with normotensive pregnancies, the arterial stiffness trajectory over the course of 1 year after delivery did not differ between women with preeclampsia and those with normotension.

\section{Results}

Systemic arterial stiffness undergoes major changes during pregnancy. Previous longitudinal studies of women with normotensive pregnancies have demonstrated that the pulse wave velocity (PWV), an index of arterial stiffness, decreases during the second trimester, increases during the third trimester and delivery, and decreases during the first month postpartum [21]. Another study longitudinally followed the changes in PWV throughout pregnancy and 1 month after delivery in women with normal pregnancies, and showed a similar pattern of change in the PWV [22]. On the other hand, other studies revealed that in patients with pregnancy-induced hypertension, the PWV did not decrease between the first and second trimesters, and markedly increased after delivery [21, 23, 24]. The key finding that is consistent in the present and previous studies is an increased postpartum arterial stiffness parameter from 7 weeks up to 2-3 years postpartum [25]. The present study showed an elevated CAVI up to 6 months postpartum. The timing and persistence of endothelial dysfunction after delivery in women with a history of preeclampsia has not been fully elucidated.

To our knowledge, this study is the first longitudinal report of arterial stiffness using the CAVI, and the results suggest that there are measurable changes in the maternal vasculature during pregnancy. 


\section{Mean CAVI over time according to group from unadjusted mixed model}

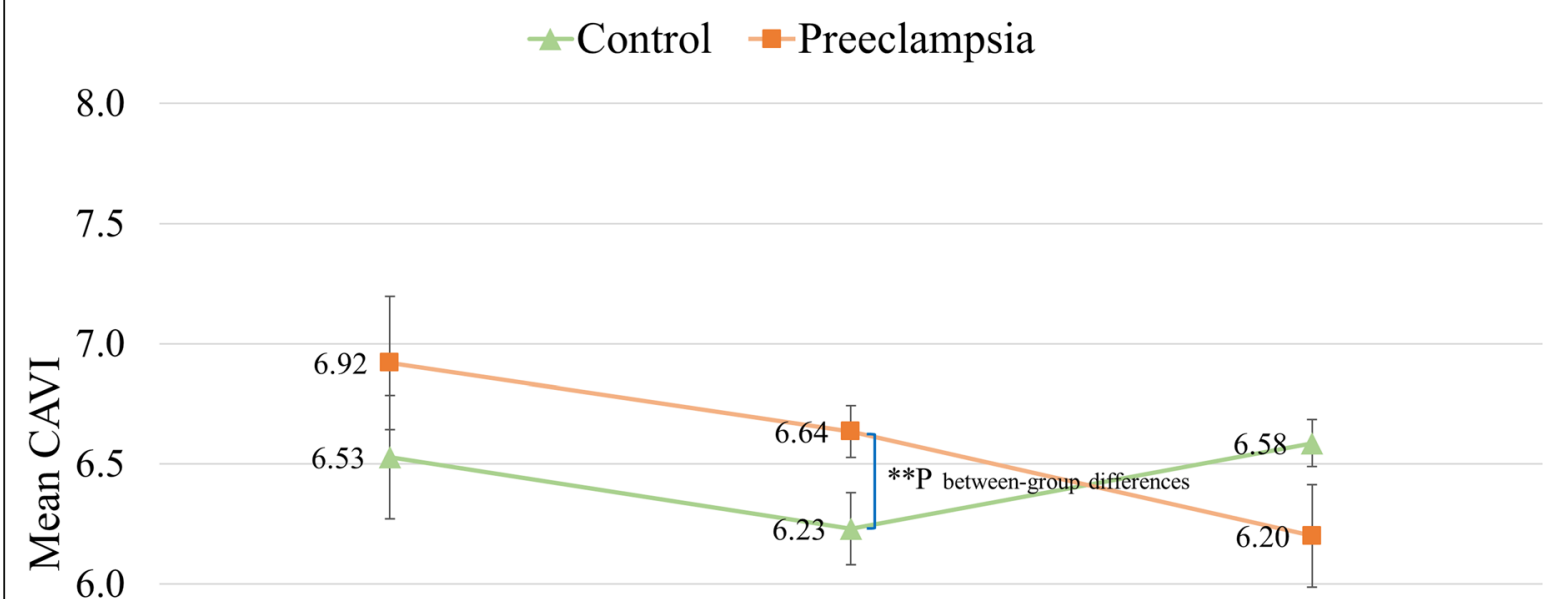

\section{5}

5.0

Day 1

6 months

12 months

Fig. 2 Mean CAVI over time according to group from unadjusted mixed modeling. Data are presented as the mean level $\pm S E$, and significant differences are indicated by double asterisks (** $p<0.05)$. CAVl, cardio-ankle vascular index; SE, standard error

Preeclampsia is associated with greater and more prolonged postpartum increases in arterial stiffness [22]. However, few studies have compared the postpartum longitudinal change in arterial stiffness between women with preeclamptic and normotensive pregnancies. Most studies utilized a cross-sectional design and estimated arterial stiffness by pulse wave analysis (PWA) $[11,26]$. $\mathrm{BP}$ is one of the most important contributing factors to PWA [27], and unfavorable arterial stiffness indices in women with a history of preeclampsia may be attributable to a higher incidence of hypertension. Thus, in the present study, we examined the longitudinal change in arterial stiffness for 1 year after delivery using the CAVI, which is less affected by BP than the PWA. We observed a significant group difference in the mean CAVI at 6 months after delivery; however, at 12 months, the group difference was no longer significant. Furthermore, the overall difference between the groups in the longitudinal change in the mean CAVI over the course of 1 year after delivery failed to reach statistical significance. This result suggests that postpartum changes in arterial stiffness in women with preeclampsia are reversible, as is the case for normotensive pregnancies.

Table 3 Within-subject (time) differences in the mean CAVI ${ }^{a}$, with comparisons between pairs of time points

\begin{tabular}{llllll}
\hline & Group & Day $\mathbf{1}$ & $\mathbf{6}$ months & 12 months & \multicolumn{1}{c}{$\boldsymbol{P}$-value } \\
\hline Mean CAVI & Control & $6.52(6.15,6.91)$ & $6.23(5.74,6.72)$ & - & 0.61 \\
& $6.52(6.15,6.91)$ & - & $6.59(6.08,7.09)$ & 0.98 \\
& & $6.23(5.74,6.72)$ & $6.59(6.08,7.09)$ & 0.57 \\
& Preeclampsia & $6.92(6.51,7.33)$ & $6.64(6.15,7.12)$ & - & 0.64 \\
& $6.92(6.51,7.33)$ & - & $6.20(5.57,6.83)$ & 0.14 \\
& - & $6.64(6.15,7.12)$ & $6.20(5.57,6.83)$ & 0.52 \\
\hline
\end{tabular}

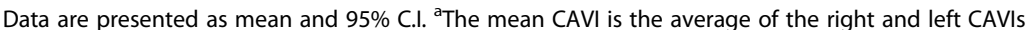
CAVI Cardio-ankle vascular index, C. I Confidence interval 
Table 4 Predictors of the longitudinal change in the mean $C A V l^{a}$ from mixed-effects modeling

\begin{tabular}{llll}
\hline & $\beta$ estimate \pm SE & 95\% C.I & $P$-value \\
\hline Time since delivery: & & & \\
$\quad$ Day 1 & - & - & \\
6 months & $-0.54 \pm 0.22$ & $-0.97,-0.11$ & 0.015 \\
12 months & $-0.62 \pm 0.24$ & $-1.10,-0.14$ & 0.012 \\
Group: & & & \\
$\quad$ Control & - & - & \\
Preeclampsia & $0.11 \pm 0.21$ & $-0.31,0.54$ & 0.600 \\
BMl & $-0.07 \pm 0.02$ & $-0.12,0.03$ & 0.003 \\
Age & $0.08 \pm 0.03$ & $0.02,0.14$ & 0.013 \\
Diabetes Mellitus: & & & \\
No & - & - & \\
$\quad$ Yes & $1.07 \pm 0.41$ & $0.25,1.89$ & 0.012 \\
$R_{(m)}^{2}=0.1528, R^{2}{ }_{(C)}=0.3624$ & & \\
\hline
\end{tabular}

${ }^{a}$ The mean CAVI is the average of the right and left CAVIs. Interactions between covariates in the final model were examined and none were found to be statistically significant

$R_{(m)}^{2}$ marginal $\mathrm{R}^{2}, R^{2}(\mathrm{C})$ conditional $\mathrm{R}^{2}$, SE Standard error, $C$. I confidence interval, BMI Body mass index

\section{Clinical implications}

In the present study, we confirmed that preeclamptic pregnancy is associated with higher postpartum trajectories of age- and time-adjusted BP and metabolic indices. These results are consistent with previous reports from Western countries [28, 29]. These factors may contribute to the development of long-term cardiovascular disease. Thus, the present results suggest that an unfavorable cardiovascular risk profile may contribute to the development of future cardiovascular disease to a greater extent than endothelial damage caused by preeclampsia persisting beyond the postpartum recovery period.

Diabetes mellitus was independently associated with an increased CAVI in the mixed-effect model. Gestational diabetes is associated with cardiovascular disease later in life, and the present results suggest that increased arterial stiffness may play a role. Women with gestational diabetes should be closely followed, even if they do not have a history of preeclampsia.

\section{Research implications}

The study results suggest that meticulous follow-up and strict control of cardiovascular disease risk factors in women with a history of preeclampsia are needed. However, to date, there is limited research evaluating the efficacy of different interventional approaches for addressing postpartum cardiovascular health in women with a history of preeclampsia.

\section{Strengths and limitations}

To the best of our knowledge, we have performed the longest follow-up study of postpartum arterial stiffness. In addition, this is the first study that compared the longitudinal change in the CAVI between postpartum women with preeclamptic and normotensive pregnancies.

The present study has several limitations. First, the sample size was relatively small; consequently, we could not confirm the effect of antihypertensive medication use on the longitudinal change in the CAVI. However, to our knowledge, no other study has been published on the longitudinal CAVI change after delivery in women with preeclampsia. Our study was an exploratory pilot study using a convenient sample from the target population. Second, only 76.7 and $61.6 \%$ of women completed the study assessments at 6 and 12 months, respectively. Participants who dropped-out were too busy with childcare to participate in the study. In South Korea, the burden of infant care is usually concentrated on mothers, and support from the welfare system is inadequate [30]. Thus, the assumption that data was missing at random is reasonable, and the use of mixed-effects modeling under this assumption was appropriate. Third, the heterogeneity of the preeclampsia population should be considered. In the present study, among patients with preeclampsia, 22 had early-onset preeclampsia, whereas 15 had late-onset preeclampsia. Although the clinical features of early- and late-onset preeclampsia overlap, they are associated with different biochemical markers, heritability, and maternal/fetal outcomes. Future studies with larger sample sizes could allow analyses to elucidate the difference in CAVI trajectory between early- and late-onset preeclampsia. Fourth, the rate of the earlyonset preeclampsia was much higher was in the present study (60\%) than in general population (12\%) [31]. Most of patients in our cohort were referred from primary and secondary maternity hospitals; referred patients were more likely to have early-onset and severe preeclampsia than those who were not referred to our hospital. Finally, we only used the CAVI to assess arterial stiffness. Other indices, such as the PWV or augmentation index, were not evaluated. However, the efficacy of the CAVI has been validated in numerous clinical conditions, and is correlated with other arterial stiffness markers $[14,15,18]$.

\section{Conclusions}

During 1 year of postpartum follow-up, women with preeclampsia showed a more unfavorable cardiovascular risk profile trajectory than pregnant women with normotension. However, there was no significant longitudinal difference in arterial stiffness between women with preeclampsia and normotensive pregnant women. Both 
Table 5 Impact of preeclampsia on longitudinal changes in blood pressure and metabolic indices

\begin{tabular}{|c|c|c|c|c|}
\hline Outcome & Covariates & $\beta$ estimate $\pm \mathrm{SE}$ & $95 \%$ C.I & $P$-value \\
\hline \multirow[t]{9}{*}{ Systolic BP (mmHg) } & Time since delivery: & & & \\
\hline & Day 1 & - & - & \\
\hline & 6 months & $-10.6 \pm 2.12$ & $-14.8,-6.41$ & $<0.0001$ \\
\hline & 12 months & $-10.3 \pm 2.36$ & $-15.0,-5.60$ & $<0.0001$ \\
\hline & Group: & & & \\
\hline & Control & - & - & \\
\hline & Preeclampsia & $21.6 \pm 2.90$ & $15.9,27.4$ & $<0.0001$ \\
\hline & Age & $0.46 \pm 0.41$ & $-0.36,1.28$ & 0.273 \\
\hline & $R_{(m)}^{2}=0.0502, R_{(C)}^{2}=$ & & & \\
\hline \multirow[t]{9}{*}{ Diastolic BP (mmHg) } & Time since delivery: & & & \\
\hline & Day 1 & - & - & \\
\hline & 6 months & $-2.75 \pm 1.46$ & $-5.66,0.16$ & 0.064 \\
\hline & 12 months & $-0.59 \pm 1.63$ & $-3.84,2.66$ & 0.720 \\
\hline & Group: & & & \\
\hline & Control & - & - & \\
\hline & Preeclampsia & $16.1 \pm 2.07$ & $12.0,20.2$ & $<0.0001$ \\
\hline & Age & $0.32 \pm 0.29$ & $-0.27,0.90$ & 0.287 \\
\hline & $R_{(m)}^{2}=0.0343, R_{(C)}^{2}=$ & & & \\
\hline \multirow[t]{9}{*}{ Waist/Hip ratio } & Time since delivery: & & & \\
\hline & Day 1 & - & - & \\
\hline & 6 months & $-0.10 \pm 0.02$ & $-0.14,-0.06$ & $<0.0001$ \\
\hline & 12 months & $-0.07 \pm 0.02$ & $-0.11,-0.04$ & 0.0001 \\
\hline & Group: & & & \\
\hline & Control & - & - & \\
\hline & Preeclampsia & $0.04 \pm 0.02$ & $0.01,0.07$ & 0.016 \\
\hline & Age & $0.006 \pm 0.002$ & $-0.011,-0.001$ & 0.012 \\
\hline & $R_{(m)}^{2}=0.0252, R_{(C)}^{2}=$ & & & \\
\hline \multirow[t]{9}{*}{ Total cholesterol (mg/dL) } & Time since delivery: & & & \\
\hline & Day 1 & - & - & \\
\hline & 6 months & $-36.7 \pm 5.69$ & $-48.1,-25.4$ & $<0.0001$ \\
\hline & 12 months & $-45.9 \pm 6.36$ & $-58.5,-33.2$ & $<0.0001$ \\
\hline & Group: & & & \\
\hline & Control & - & - & \\
\hline & Preeclampsia & $20.5 \pm 9.23$ & $2.08,38.8$ & 0.030 \\
\hline & Age & $-0.14 \pm 1.30$ & $-2.73,2.44$ & 0.913 \\
\hline & $R_{(m)}^{2}=0.1370, R_{(c)}^{2}=$ & & & \\
\hline \multirow[t]{8}{*}{ LDL cholesterol (mg/dL) } & Time since delivery: & & & \\
\hline & Day 1 & - & - & \\
\hline & 6 months & $-14.3 \pm 4.59$ & $-23.4,-5.14$ & 0.003 \\
\hline & 12 months & $-20.7 \pm 5.15$ & $-31.0,-10.5$ & 0.0001 \\
\hline & Group: & & & \\
\hline & Control & - & - & \\
\hline & Preeclampsia & $51.5 \pm 30.8$ & $-9.82,112.9$ & 0.099 \\
\hline & Age & $-4.50 \pm 4.31$ & $-13.1,4.09$ & 0.30 \\
\hline
\end{tabular}


Table 5 Impact of preeclampsia on longitudinal changes in blood pressure and metabolic indices (Continued)

\begin{tabular}{|c|c|c|c|c|}
\hline Outcome & Covariates & $\beta$ estimate \pm SE & $95 \%$ C.I & $P$-value \\
\hline & $R_{(m)}^{2}=0.4839, R^{2}$ & & & \\
\hline \multirow[t]{9}{*}{$\mathrm{TG}(\mathrm{mg} / \mathrm{dL})$} & Time since delive & & & \\
\hline & Day 1 & - & - & \\
\hline & 6 months & $-119.5 \pm 12.5$ & $-144.3,-94.7$ & $<0.0001$ \\
\hline & 12 months & $-127.9 \pm 13.8$ & $-155.5,-100.3$ & $<0.0001$ \\
\hline & Group: & & & \\
\hline & Control & - & - & \\
\hline & Preeclampsia & $31.7 \pm 15.7$ & $0.41,62.9$ & 0.047 \\
\hline & Age & $-0.41 \pm 2.28$ & $-4.96,4.13$ & 0.857 \\
\hline & $R_{(m)}^{2}=0.0288, R^{2}$ & & & \\
\hline \multirow[t]{9}{*}{ HDL cholesterol (mg/dL) } & Time since delive & & & \\
\hline & Day 1 & - & - & \\
\hline & 6 months & $-5.15 \pm 1.78$ & $-8.68,-1.61$ & 0.005 \\
\hline & 12 months & $-5.17 \pm 1.98$ & $-9.12,-1.23$ & 0.011 \\
\hline & Group: & & & \\
\hline & Control & - & - & \\
\hline & Preeclampsia & $-1.80 \pm 2.73$ & $-7.25,3.64$ & 0.511 \\
\hline & Age & $-0.23 \pm 0.39$ & $-1.01,0.55$ & 0.558 \\
\hline & $R_{(m)}^{2}=0.0878, R^{2}$ & & & \\
\hline \multirow[t]{9}{*}{ Creatinine $(\mathrm{mg} / \mathrm{dL})$} & Time since delive & & & \\
\hline & Day 1 & - & - & \\
\hline & 6 months & $-0.002 \pm 0.022$ & $-0.046,0.041$ & 0.913 \\
\hline & 12 months & $0.025 \pm 0.024$ & $-0.024,0.073$ & 0.310 \\
\hline & Group: & & & \\
\hline & Control & - & - & \\
\hline & reeclampsia & $0.115 \pm 0.041$ & $0.032,0.197$ & 0.007 \\
\hline & Age & $-0.01 \pm 0.006$ & $-0.021,0.002$ & 0.089 \\
\hline & $R_{(m)}^{2}=0.0702, R^{2}$ & & & \\
\hline \multirow[t]{9}{*}{ AST (IU/L) } & Time since delive & & & \\
\hline & Day 1 & - & - & \\
\hline & 6 months & $-6.07 \pm 2.11$ & $-10.3,-1.88$ & 0.005 \\
\hline & 12 months & $-6.49 \pm 2.31$ & $-11.1,-1.89$ & 0.006 \\
\hline & Group: & & & \\
\hline & Control & - & - & \\
\hline & Preeclampsia & $4.78 \pm 1.78$ & $1.22,8.35$ & 0.009 \\
\hline & Age & $-0.15 \pm 0.27$ & $-0.69,0.39$ & 0.576 \\
\hline & $R_{(m)}^{2}=$ Not Availd & ot Available & & \\
\hline \multirow[t]{7}{*}{ ALT (IU/L) } & Time since delive & & & \\
\hline & Day 1 & - & - & \\
\hline & 6 months & $-3.00 \pm 2.97$ & $-9.91,2.90$ & 0.315 \\
\hline & 12 months & $-6.55 \pm 3.27$ & $-13.1,-0.045$ & 0.049 \\
\hline & Group: & & & \\
\hline & Control & - & - & \\
\hline & Preeclampsia & $7.23 \pm 2.86$ & $1.53,12.9$ & 0.014 \\
\hline
\end{tabular}


Table 5 Impact of preeclampsia on longitudinal changes in blood pressure and metabolic indices (Continued)

\begin{tabular}{lllll}
\hline Outcome & Covariates & $\boldsymbol{\beta}$ estimate \pm SE & 95\% C.I & $-0.83,0.86$ \\
\hline Age & $0.016 \pm 0.43$ & \\
$R_{(m)}^{2}=0.0087, R_{(c)}^{2}=0.0652$ & & \\
\hline
\end{tabular}

${ }^{a}$ There is a case where a variance component is zero or very near zeros in mixed models, and thus $R^{2}$ cannot be calculated $R_{(m)}^{2}$ marginal $R^{2}, R_{(C)}^{2}$ conditional $R^{2}$, SE Standard error, $C$. I Confidence interval, BP Blood pressure, LDL Low-density lipoprotein, TG Triglyceride, HDL High-density lipoprotein, AST Aspartate transaminase, ALT Alanine aminotransferase

groups did, however, experience a decrease in arterial stiffness, which appeared to persist after 6 months postpartum. Our findings suggest that meticulous follow-up and strict control of cardiovascular disease risk factors in women with a history of preeclampsia are advisable.

\section{Abbreviations}

AST: Aspartate transaminase; ALT: Alanine transaminase; BMI: Body mass index; BP: Blood pressure; CAVI: Cardio-ankle vascular index; HDL: Highdensity lipoprotein; LDL: Low-density lipoprotein; TG: Triglyceride; PWA: Pulse wave analysis; PW: Pulse wave velocity; SNUBH: Seoul National University Bundang Hospital; IRB: Institutional review board

\section{Acknowledgements}

The authors thank all the staff and patients involved in this research.

\section{Authors' contributions}

SK: Writing - original draft, Investigation, Visualization; HJL: Methodology, Formal Analysis, Data curation; JRK: Investigation; KJO: Methodology,

Supervision, Validation, Writing - Reviewing \& Editing; JSH:

Conceptualization, Supervision, Validation, Writing - Reviewing \& Editing; JWS: Conceptualization, Methodology, Project administration, Writing Reviewing \& Editing. All authors have read and approved the final version of the manuscript.

\section{Funding}

This study was supported by a grant from the Seoul National University Bundang Hospital Research Fund (02-2013-077). The funding institution had no role in the design, conduct, analysis, and interpretation of the findings, or in the decision to publish.

\section{Availability of data and materials}

Data cannot be made publicly available due to ethical restrictions set by the IRB of Seoul National University Bundang Hospital; i.e., public availability would compromise patient confidentiality and participant privacy. Please contact the corresponding author to request the minimal anonymized dataset.

\section{Ethics approval and consent to participate}

This study was approved by the Institutional Review Board (IRB) of Seoul National University Bundang Hospital (SNUBH), South Korea (IRB No. B-1402240-006). Written informed consent was obtained from all participants before enrolment.

\section{Consent for publication}

Not applicable.

\section{Competing interests}

The authors declare no conflict of interest.

\section{Author details}

'Department of Internal Medicine, Seongnam Citizens Hospital, Seongnam, Republic of Korea. ${ }^{2}$ Department of Community Health \& Epidemiology, College of Medicine, University of Saskatchewan, Saskatoon, Canada. ${ }^{3}$ Department of Internal Medicine, Cardiovascular Center, Seoul National University Bundang Hospital, Seoul National University College of Medicine, 82 Gumi-ro, 173 Beon-gil, Bundang-gu, Seongnam 13620, Republic of Korea. ${ }^{4}$ Department of Obstetrics and Gynecology, Seoul National University
Bundang Hospital, Seoul National University College of Medicine, 82 Gumi-ro, 173 Beon-gil, Bundang-gu, Seongnam 13620, Republic of Korea.

Received: 24 June 2020 Accepted: 28 October 2020

Published online: 11 November 2020

\section{References}

1. Steegers EA, von Dadelszen P, Duvekot JJ, Pijnenborg R. Pre-eclampsia. Lancet. 2010;376(9741):631-44.

2. Khan KS, Wojdyla D, Say L, Gulmezoglu AM, Van Look PF. WHO analysis of causes of maternal death: a systematic review. Lancet. 2006;367(9516):106674.

3. Duley L. The global impact of pre-eclampsia and eclampsia. Semin Perinatol. 2009;33(3):130-7.

4. Roberts JM, Cooper DW. Pathogenesis and genetics of pre-eclampsia. Lancet. 2001:357(9249):53-6.

5. Seely EW, Solomon CG. Insulin resistance and its potential role in pregnancy-induced hypertension. J Clin Endocrinol Metab. 2003;88(6):23938.

6. Greer IA. Thrombosis in pregnancy: updates in diagnosis and management. Hematol Am Soc Hematol Educ Program. 2012;2012:203-7.

7. Bellamy L, Casas JP, Hingorani AD, Williams DJ. Pre-eclampsia and risk of cardiovascular disease and cancer in later life: systematic review and metaanalysis. BMJ. 2007;335(7627):974

8. McDonald SD, Malinowski A, Zhou Q, Yusuf S, Devereaux PJ. Cardiovascular sequelae of preeclampsia/eclampsia: a systematic review and meta-analyses. Am Heart J. 2008;156(5):918-30.

9. Zieman SJ, Melenovsky V, Kass DA. Mechanisms, pathophysiology, and therapy of arterial stiffness. Arterioscler Thromb Vasc Biol. 2005;25(5):932-43.

10. Chae CU, Pfeffer MA, Glynn RJ, Mitchell GF, Taylor JO, Hennekens CH. Increased pulse pressure and risk of heart failure in the elderly. JAMA. 1999; 281(7):634-9.

11. Namugowa A, Iputo J, Wandabwa J, Meeme A, Buga GAB. Comparison of arterial stiffness in preeclamptic and normotensive pregnant women from a semi-rural region of South Africa. Clin Exp Hypertens. 2017;39(3):277-83.

12. Torrado J, Farro I, Zocalo Y, Farro F, Sosa C, Scasso S, et al. Preeclampsia is associated with increased central aortic pressure, elastic arteries stiffness and wave reflections, and resting and Recruitable endothelial dysfunction. Int J Hypertens. 2015;2015:720683.

13. Hypertension in Pregnancy: Executive Summary. Obstet Gynecol 2013, 122(5): 1122-1131.

14. Sun CK. Cardio-ankle vascular index (CAVI) as an indicator of arterial stiffness. Integr Blood Press Control. 2013;6:27-38.

15. Hayashi K, Yamamoto T, Takahara A, Shirai K. Clinical assessment of arterial stiffness with cardio-ankle vascular index: theory and applications. J Hypertens. 2015;33(9):1742-57 discussion 1757.

16. Shirai K, Hiruta N, Song M, Kurosu T, Suzuki J, Tomaru T, et al. Cardio-ankle vascular index (CAVI) as a novel indicator of arterial stiffness: theory, evidence and perspectives. J Atheroscler Thromb. 2011;18(11):924-38.

17. Topouchian J, Agnoletti D, Blacher J, Youssef A, Ibanez I, Khabouth J, et al. Validation of four automatic devices for self-measurement of blood pressure according to the international protocol of the European Society of Hypertension. Vasc Health Risk Manag. 2011;7:709-17.

18. Yambe T, Yoshizawa M, Saijo Y, Yamaguchi T, Shibata M, Konno S, et al. Brachio-ankle pulse wave velocity and cardio-ankle vascular index (CAVI). Biomed Pharmacother. 2004;58(Suppl 1):S95-8.

19. Nakagawa S, Schielzeth $H$. A general and simple method for obtaining R2 from generalized linear mixed-effects models. Methods Ecol Evol. 2013;4(2): $133-42$.

20. Jaeger BC, Edwards LJ, Das K, Sen PK. An R2 statistic for fixed effects in the generalized linear mixed model. J Appl Stat. 2017;44(6):1086-105. 
21. Oyama-Kato M, Ohmichi M, Takahashi K, Suzuki S, Henmi N, Yokoyama Y, et al. Change in pulse wave velocity throughout normal pregnancy and its value in predicting pregnancy-induced hypertension: a longitudinal study. Am J Obstet Gynecol. 2006;195(2):464-9.

22. Robb AO, Mills NL, Din JN, Smith IB, Paterson F, Newby DE, et al. Influence of the menstrual cycle, pregnancy, and preeclampsia on arterial stiffness. Hypertension. 2009;53(6):952-8.

23. Enkhmaa D, Wall D, Mehta PK, Stuart JJ, Rich-Edwards JW, Merz CN, et al. Preeclampsia and vascular function: a window to future cardiovascular disease risk. J Women's Health (Larchmt). 2016;25(3):284-91.

24. Christensen M, Kronborg CS, Eldrup N, Rossen NB, Knudsen UB. Preeclampsia and cardiovascular disease risk assessment - do arterial stiffness and atherosclerosis uncover increased risk ten years after delivery? Pregnancy Hypertens. 2016;6(2):110-4.

25. Kirollos S, Skilton M, Patel S, Arnott C. A systematic review of vascular structure and function in pre-eclampsia: non-invasive assessment and mechanistic links. Front Cardiovasc Med. 2019;6:166.

26. Paez O, Alfie J, Gorosito M, Puleio P, de Maria M, Prieto N, et al. Parallel decrease in arterial distensibility and in endothelium-dependent dilatation in young women with a history of pre-eclampsia. Clin Exp Hypertens. 2009; 31(7):544-52.

27. Kim EJ, Park CG, Park JS, Suh SY, Choi CU, Kim JW, et al. Relationship between blood pressure parameters and pulse wave velocity in normotensive and hypertensive subjects: invasive study. J Hum Hypertens. 2007;21(2):141-8.

28. Rana S, Lemoine E, Granger J, Karumanchi SA. Preeclampsia. Circ Res. 2019; 124(7):1094-112.

29. Breetveld NM, Ghossein-Doha C, van Kuijk SM, van Dijk AP, van der Vlugt MJ, Heidema WM, et al. Prevalence of asymptomatic heart failure in formerly pre-eclamptic women: a cohort study. Ultrasound Obstet Gynecol. 2017;49(1):134-42

30. Kim C. In South Korea, childcare burden derails women's careers; 2015. https://www.reuters.com/article/us-southkorea-women-childcare/in-southkorea-childcare-burden-derails-womens-careers-idUSKBNOLO0B220150127.

31. Lisonkova S, Joseph KS. Incidence of preeclampsia: risk factors and outcomes associated with early- versus late-onset disease. Am J Obstet Gynecol. 2013;209(6):544.e541.

\section{Publisher's Note}

Springer Nature remains neutral with regard to jurisdictional claims in published maps and institutional affiliations.

Ready to submit your research? Choose BMC and benefit from:

- fast, convenient online submission

- thorough peer review by experienced researchers in your field

- rapid publication on acceptance

- support for research data, including large and complex data types

- gold Open Access which fosters wider collaboration and increased citations

- maximum visibility for your research: over $100 \mathrm{M}$ website views per year

At $\mathrm{BMC}$, research is always in progress.

Learn more biomedcentral.com/submissions 